\title{
Cyber-Wazi: Towards a Mobile Technology-Based Soft Measure Framework Aimed at Tackling Violent Ideologies
}

\author{
Okolo, O., Adegbenro, R.D., Longe, O.B., ${ }^{4}$ Wada, F.J \& ${ }^{5}$ Danquah, P.A. \\ ${ }^{1}$ Information Literacy Unit, 2Information Systems Unit, 3Information Systems Department \\ American University of Nigeria, Yola, Adamawa State, Nigeria \\ 4Barney School of Business, University of Hartford, West Hartford, CT 06117 \\ ${ }^{5}$ Council for Scientific and Industrial Research - Institute for Scientific and Technological Information (CSIR- \\ INSTI), Accra, GhanaE-mails: ${ }^{10}$ machi.okolo@aun.edu.ng; 2dimeji.adegbenro@aun.edu.ng; \\ 3olumide.longe@aun.edu.ng, 4Wada@hartford.edu; ${ }^{3}$ danquahpaul@gmail.com
}

\begin{abstract}
The war on terror and its mitigating initiatives have taken several dimensions in the North-Eastern Nigeria. Efforts are usually directed towards countering insurgency and further mitigates the loss of lives and property that has become a common place in the region. The predominant measure taken so far by the Nigerian government has been the overstated potency of hard power (use of security forces), attempted dialogue with the terrorist and integration of deradicalized terrorist into the society, and currently the establishment of the north-eastern commission to create jobs and development in the region. These strategies though provided some semblance of sanity has not yielded expected outcomes which is to bring insurgency to a halt. This work attempts to initiate a research direction by initiating a mobile-technology-based soft measure that attempts to tackle the challenges of insurgency from a different perspective using what we now refer to as "cyber-wazi". We coined the word "Cyber-wazi" from as a combination of an English and Hausa word where the Hausa word "Wazi" means religious preaching. Attempts to re-orientate in time past through physical presence of mediators and preachers of peace have been met by resistance and violence; in some cases, resulting in death and destruction. We present a preliminary research agenda to address the identified problems.
\end{abstract}

Keywords: Terrorism, Soft model, violent ideology, religion, extremism, mobile systems, radicalization, Nigeria

iSTEAMS Multidisciplinary Conference Proceedings Reference Format

Okolo, O., Adegbenro, R.D. \& Longe, O.B. (2019): Cyber-Wazi: Towards a Mobile Technology-Based Soft Measure Framework Aimed at Tackling Violent Ideologies. Proceedings of the 20th iSTEAMS Multidisciplinary Trans-Atlantic Conference, KEAN University, New Jersey, United States of America. $10^{\text {th }}-12^{\text {th }}$ October, 2019. Pp 191-198 www.isteams.net/usa2019 - DOI Affix - https://doi.org/ 10.22624/AIMS/iSTEAMS-2019/N20N1P18

\section{INTRODUCTION}

Information technology revolution and its associated tools have touched every aspect of our lives in monumental proportion, but little attention has been given to the section of the society who by the limitations of the socioeconomic indexes has been denied access to acquire and use these tools (IT non-users). The fallout of this deprivation on these vulnerable youth populations who intends to make something good out of their lives has become a point of recruitment by extremist to beguile them as a cover-up in camps for ICT training, smart phone distribution as palliatives to demean the unjust society designed by educated elites. 
There is untapped possibility inherent in the use of smart phones and its application in combating violent extremism and ensuring peaceful co-existence by conquering the cyberspace currently dominated by extremists. Smart phone technology now serves as a tool predominantly used for accessing the internet and dissemination of information. The accessibility, reduction in cost, portability, and increase in functionality as well as user-friendliness allows individual to view it as an ideal tool for communication, create and share content with others around the world. This gives free mouthpiece to anyone with the time and inclination to make their voice heard through the use social engagement through smart phone applications (Holt \& Bossler, 2016). The deluxe of information that has shaped the society ideological leaning nowadays stem from social media ecosystem accessible mostly through the smart phone, it will be risky to de-emphasize the imperative of constructing a peaceful narrative using smart phone.

Research has shown that apart from the underlining casual factors of insurgency such as bad governance, the widespread failures of state policies, endemic corruption, poverty, unemployment, and underdevelopment in the north-eastern region of Nigeria (Uzodike \& Maiangwa, 2012), these not-withstanding, the prime trigger of violent extremism among the youths in the north-eastern part of Nigeria is radical ideologies and erroneous interpretations of religious teachings that stemmed from religious leaders (Botha \& Abdile, 2019). Recently, terrorist have also exploited computer technologies such as YouTube and other social networking sites to their advantage, they use them to disseminate their violent point of views to people. Similarly, they utilize the internet and cellular telephony to recruit, disseminate and share their extremist ideologies (Britz, 2010; Denning, 2011; Forest, 2009; Gruen, 2005).

The greater percentages of these youth often radicalized are from the disadvantaged socio-economic and educational backgrounds. These groups are easily lured and indoctrinated to imbibe extremist ideologies because of their vulnerable backgrounds. Seminal literature have revealed that the prevalent practical means to counter radicalization and violent crimes, especially the ones precipitated by ideologies either online or physical contacts have been the combined effort of governments, civil society, policy makers, social media and technology firms. They use measures such as flagging and takedowns of terrorist content, and account suspensions, and employment of at-risk youths to counter violent extremist through technological communications (Bloom \& Daymon, 2018). However, there is a paucity of literature on the use of soft-power inherent in the use of smart phone technology known as Cyber-wazi to produce contents that has a blend of religious and cultural views to counter narrative of the extremist worldviews exacerbated by the revered voices of religious and ethnic leaders often termed sacred.

\subsection{Cyber-wazi Explained}

Wazi is a Hausa word for religious preaching. It has become double-edge sword for religious adherents and those who radicalized people under the guise of religious teaching. To this end, this study intends to contextualized a framework within cyber space by using a specialized smart phone applications known as Cyber-wazi as subset of any social media network to disseminate religious and peace-inspired messages to the target demography likely to be radicalized with a view of changing the radical ideological narratives that has always been the water-shed of extremist in the north-eastern region of Nigeria, this concept is carefully crafted to re-echo the existing vocabulary of disseminating religious teaching known in Hausa as "wazi", in our adaptation we coined the term as "cyber-wazi". This study intends to suggest a smart phone application to disseminate the religious and cultural teachings as a way to counter the narrative of extremists; this is based on our hypotheses that violent extremism are inherently ideological warfare that could be effectively countered by ideological re-orientation. We suggest a social, cultural, technological, religious and conceptual framework that could re-orientate the discourse on combating extremism. 
The rest of the paper is organized as follows: in Section 2, we review the related literature. In Section 3, we present theories for countering the violent extremism. In section 4, we present research problem and objectives as well as research directions by using cyber-wazi applications and other constructs for combating violent extremism in the north-eastern part of Nigeria. In Section 5, we present the mathematical model that based on our theories. Finally, we provide the conclusion and future work in Section 6.

\section{RELATED WORKS}

We summarize the literature in the related areas: the dominant strategy against violent extremism in the northeastern Nigeria, the changing dynamics of counter-terrorism in the $21^{\text {st }}$ century, and soft power, Smart phone technology and counter terrorism.

\subsection{The dominant strategy against violent extremism in the North-eastern Nigeria}

At the outset of the violent extremism rampage in 2009 which caused an untold loss of life, property and livelihood in the region and a near-anarchy of the whole country in 2013-2015, the country was caught offguard. Since too little was known about violent extremism, no strategy and comprehensive plan, therefore, the initial reaction of the government was the inevitable military onslaught against the insurgents. The overstated forceful encounter was valid owing to the carnage, but the outcome of the success was very relative as it effectiveness was not holistic, but further it exposed the level of corruption, strategy and indecisiveness of both civilian and military hierarchy to quell the uprising (Bappah, 2016; Campbell, 2014; Varin, 2018).

Thereafter, dialogue and negotiation was later initiated as an alternative measure in the wake of kidnap of Chibok girls to secure their release because of the global outrage (Nwankpa, 2017). While these measures are of immediate relevance, these could not secure peace in the long term, there are other complimentary measure that should support military strategy. Abdulazeez (2015) studies offered other alternatives that could ensure long-term peace, these are comprehensive economic and social reforms through provision of jobs, education for the highly out of schools children that potentially breeds extremism and proper management of the humanitarian displacement situation in the region. Other alternative such as the use of technology to tackle the ideological foundation of terrorism is considered in this study.

\subsection{The changing dynamics of Counter-terrorism in the 21 st century}

The brutal onslaught by security agencies coupled with increasing policing of social media platforms against terrorist have led to the group's loss of physical territory. However, the terrorist have exploited the other virtual platforms such as a messaging application for clandestine propaganda and recruiting new member. Bloom and Daymon (2018) study investigated the future threats and ISIS's caliphate and revealed that the groups have been using Telegram by manipulating the anonymity feature of the Telegram application with enhanced addictive and rich online environment for group identity, shared opinions, and dominant ideologies. Edwards and Gribbon (2013) investigated the use of technology in radicalization in the United Kingdom by interviewing terrorists allegedly recruited online; they discovered that the current process of radicalization is done secretly. In most cases people who do not normally go for religious gathering to partake in radical views turn to the use of technology to find information in line with extreme beliefs. From these studies, it was crystal clear that the modes of operation of terrorists have morphed to a more technological dimension, especially the use of social media applications which are readily available on smart phone. 
Ogunlana (2019) re-echoed the changing the tactics of the 21st-century terrorists approach now acquiring technological capabilities for destructive mission such as cyberterrorism, pervert doctrines and falsehood, blackmail guided by religious radical ideologies that are currently affecting the dynamics of conflict. It therefore becomes imperative to investigate this new trend of cyber-terrorism.

\subsection{Soft power, Smart phone technology and counter terrorism}

Research in computers and smart phone technology has gained prominence using the utilitarian constructs i.e communications, business and learning in a most pervasive ways. However, they have not been a sustained effort to double-down on how the soft power in smart phones technology can be used to combat violent extremism. Soft power as coined by Pamment (2016) is the ability to diplomatically influence the behavior of others without the use of force, but by using persuasion and argument to desire your intended outcome in the life of the targeted audience. In other words, soft power has an attractive force that can acquiesce and ensure common grounds in comparative views. Soft power was previously an exclusive reserve of politics and public diplomacy, but currently, when judging from the social cohesion made available from smart phone technology, it is clear that the terrorist groups employ these same tactics to foster common grounds, indoctrinate, radicalize, recruit, and other operational planning (Blechman, 2004).

Smart phone technology and applications, possesses both soft power as well as smart power. Its addictive power can affect an outcome on the target audience behaviorally, and cause the target audience to be receptive to the dominant message on the applications. The smart phone and social media applications have an alluring function for bonding, propaganda, user engagement, radicalization, and recruitment because of their addictive qualities (Bloom \& Daymon, 2018). To achieve an ultimate power in the fight against violent extremist, they must a conscious and strategic combination of hard and soft power. The reach of this study is to explore this stand point.

\section{CONCEPTUAL FRAMEWORK}

To guide this research, we employed two theories: Information diffusion and agent based model to support our attempts.

\subsection{Information Diffusion Theory}

Diffusion of information is a theory that attempt to unravel how information, ideas, or innovation are propagated in a social system (Yang et al., 2015). The main determinant of information diffusion is the influence of the individual nodes (users in a social system or social networks). How information may diffuse in a network is affected by the structure of the network, in which users' structural properties reflect their social roles in different socio-religious and traditional settings. Roles played by different actors in information diffusion process are determined by the influence a given actor has on other actors in a given environment. Social media such as twitter demonstrates how an information diffuses in the network, a tweet on a Twitter application corresponds to a piece of information and the rate of diffusion is shown by the number of retweet, Lou and Tang (2013) revealed that $25 \%$ of information diffusion on most social media is initiated by $1 \%$ of users that occupies a central social roles and who are bridges between otherwise disconnected communities in a network. The buzz and retweet and the level of information diffusion in a social environment originated from opinion leaders, celebrities, religious and traditional leaders, hence every information have larger diffusion scales but also have longer lifespans of diffusion. In our research direction, we propose that social, religious and traditional roles can be used to diffuse counter violent ideological messages with the development of cyber-wazi application. 


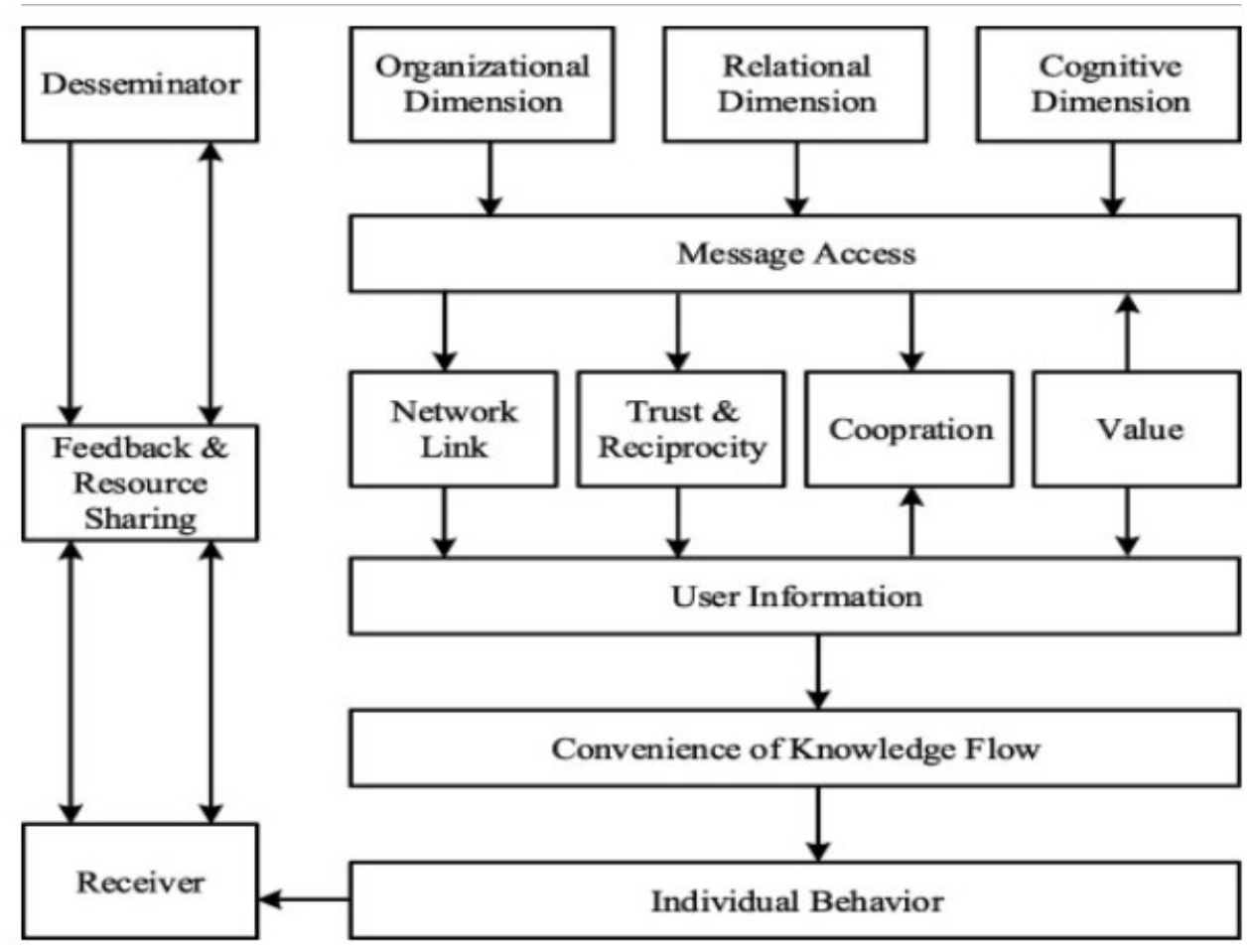

Fig 1: Components of Information Diffusion Model

(Source: Razaque et al., 2019)

\subsection{Agent-Based Model}

Agent-based modelling (ABM) is an approach to modelling systems consisting of autonomous, interacting agents (Macal \& North, 2010). It is a way to model the dynamics of complex systems and other adaptive systems. Agent-based models simulate the behavior of agents (human or otherwise) used to observe the collective effects of behaviors and interactions. The development of agent modelling tools has brought about by advances in computation have made possible an increase in agent-based applications across a variety of domains and disciplines. Agent-based modelling provides a way to model social systems that are made up of agents who interact with and influence each other, learn from their experiences, and adapt their behaviors so they are better suited to their environment.

In other words, their behavior must be adaptive, able to learn and change its behaviors in response to its experiences, to be called an agent. In this study, the agents are opinion leaders (religious or traditional) whose can influence the behaviors of other agents or the member of the society by information that cascades from them. Opinion leaders exerts two types of interpersonal influence, these are informational and normative influence. Informational influence is the level of acceptance of a given information by others based on evidence of reality. Religious and traditional opinion leaders in the north exert high level of influence on the people within their jurisdiction. Making them a vanguard of peace and non-violent messages using smart phone applications would have a far-reaching impact on counteracting the wrong religious ideology that has precipitated terrorism Normative influence, on the other hand, use the status compliance on other members of the society to affect their cognitive disposition to violence. 
Hence, normative traditional and religious opinion leaders can effectively exert social pressure and social support and thereby influence decision-making processes of the people in regards to ideology. Since people aim to create and maintain meaningful social relationships, they often engage in behaviors approved by opinion leaders, such as adopting a peace message to appeal to their leaders (Eck et al., 2011). Even privately consumed information prioritize the informational influence for conformity, therefore, publicly consumed information are greatly influenced by informational and normative influence of opinion leaders in the war against wrong ideology. We assume that religious and traditional opinion leaders play an important role in the diffusion of peace related information in the north. Opinion leaders may influence the spread process of counterideological information by increasing the speed of diffusion to have the maximum impact on the target population.

\section{RESEARCH PROBLEM}

Terrorism has grown in leaps and bounds transcending form a local to an international dimension, therefore, it is important to think globally and act locally in addressing the menace in Northern Nigeria. One of the areas that has not been holistically considered in addressing the ideological foundation of terrorism is the use of technology, especially the smart phones and it associated communication applications.

Nosiri and lbekwe, (2016) posited that globalizations arising from the growth in information and communication technology possess a great challenge to the war of terrorism. This is because terrorists have established an effective link with other international violent groups through information and knowledge sharing, fund raising and recruitment through the use of technology. Based on this, it is important to note that the insurgency in the north-eastern Nigeria is not an isolated incidence; therefore, the solution should be far-reaching to inculcate the technological approach.

Violent extremism is an off-shoot of indoctrination and wrong interpretation of cultural and religious ideology, to devise a robust counter-insurgency approach, the often overlooked "information" element should be duly considered. While, there is an overwhelming judgement of the effect of incendiary preaching on radicalization, the use of ubiquitous technology such as smart phones and it application have not been considered.

\subsection{Research Aims and Objectives}

The research aims to investigate the use of smart applications, known as cyber-wazi to combat violent extremism. The specific objectives are:

i. Study the effect of sermons/wazi on radicalization of youth in the north-eastern Nigeria

ii. $\quad$ Evaluate the role of opinion leaders in counteracting radicalization

iii. Develop a framework/model based on the theories that can be used to disseminate counterterrorism messages with the aid of cyber-wazi

\subsection{Research Directions}

We intend to present a research framework based on information diffusion and agent based network. This research focuses mainly on how efficiently can information (wazi) flows through a social network ecosystem to counter the violent narratives of terrorist by using cyber-wazi. The cyber-wazi group would be integrated into the social media networks to selectively monitor and review clandestine activities of terrorist and respond promptly by posting peace-inspired messages to counter the violent ideological messages of the violent group. We have allotted high weight to religious teaching as the off-shoot of radicalization from our preliminary investigations and that cyber-wazi construct could counter the effect of this ideological nuance. 


\section{CONCLUSION AND DIRECTION FOR FUTURE WORK}

This research presents new vista of approach to counter terrorism using ideological dimension. The framework would need to be tested with real-life data using the weighted influence of the agents/opinion leaders used in the model with a view to determining the effectiveness.

Future work would simulate the impact of opinion leaders on information diffusion and the effectiveness of our model.

\section{REFERENCES}

1. Abdulazeez, M. . (2015). The Inadequacies of Exclusive Military Action: Countering Boko Haram's Terrorism with Alternative Approaches. Excellence In. Terrorism Expert Conference, Warsaw. Bappah, H. Y. (2016). Nigeria's military failure against the Boko Haram insurgency. African Security Review, 25(2), 146-158. https://doi.org/10.1080/10246029.2016.1151799

2. Blechman, B. M. (2004). Soft Power: the Means to Success in World Politics. Political Science Quarterly, 119(4), 680-682.

3. Bloom, M., \& Daymon, C. (2018). Assessing the Future Threat: ISIS's Virtual Caliphate. Orbis, 62(3), 372-388. https://doi.org/10.1016/j.orbis.2018.05.007

4. Botha, A., \& Abdile, M. (2019). Reality Versus Perception: Toward Understanding Boko Haram in Nigeria. Studies in Conflict \& Terrorism, 42(5), 493-519. https://doi.org/10.1080/1057610X.2018.1403152

5. Britz, T. . (2010). Terrorism and technology: Operationalizing cyberterrorism and identifying concepts. In Crime on -line: Correlates, causes, and context (pp. 193-220). Carolina Academic Press.

6. Campbell, J. (2014). U.S. Policy to Counter Nigeria's Boko Haram. Council on Foreign Relations.

7. Denning, D. . (2011). Cyber-Conflict as an Emergent Social Problem. In Corporate Hacking and Technology-Driven Crime: Social Dynamics and Implications (pp. 170-186). IGI-Global.

8. Eck, P. S. van, Jager, W., \& Leeflang, P. S. H. (2011). Opinion Leaders' Role in Innovation Diffusion: A Simulation Study. Journal of Product Innovation Management, 28(2), 187-203. https://doi.org/10.1111/j.1540-5885.2011.00791.x

9. Edwards, C., \& Gribbon, L. (2013). Pathways to Violent Extremism in the Digital Era. The RUSI Journal, 158(5), 40-47. https://doi.org/10.1080/03071847.2013.847714

10. Forest, J. . (2009). Influence Warfare: How Terrorists and Governments Struggle to Shape Percep tions in a War of Ideas. ABC-CLIO.

11. Gruen, M. (2005). Innovative recruitment and indoctrination tactics by extremists: Video games, hip hop, and the World Wide Web. In The making of a terrorist. ABC-CLIO.

12. Holt, T. ., \& Bossler, A. . (2016). Technology and Violence. In The Wiley Handbook on the Psychology of Violence (First edition). John Wiley \& Sons, Ltd.

13. Lou, T., \& Tang, J. (2013). Mining structural hole spanners through information diffusion in social networks. Proceedings of the 22nd International Conference on World Wide Web, 825-836. https://doi.org/10.1145/2488388.2488461

14. Macal, C. M., \& North, M. J. (2010). Tutorial on agent-based modelling and simulation. Journal of Simulation, 4(3), 151-162. https://doi.org/10.1057/jos.2010.3 
15. Nosiri, U. \& Ibekwe, E. . (2016). Globalization: A challenge to counter terrorism in Nigeria. Clabar Journal of the Humanities, 175-187.

16. Nwankpa, M. (2017). Dialoguing and negotiating with terrorists: any prospect for Boko Haram? Behavioral Sciences of Terrorism and Political Aggression, 9(2), 106-124. https://doi.org/10.1080/19434472.2016.1189445

17. Ogunlana, S. O. (2019). Halting Boko Haram / Islamic State's West Africa Province Propaganda in Cyberspace with Cybersecurity Technologies. Journal of Strategic Security, 12(1), 72-106. JSTOR.

18. Pamment, J. (2016). British Public Diplomacy and Soft Power: Diplomatic Influence and the Digital Revolution. Springer.

19. Razaque, A., Rizvi, S., khan, M. J., Almiani, M., \& Rahayfeh, A. A. (2019). State-of-art review of information diffusion models and their impact on social network vulnerabilities. Journal of King Saud University - Computer and Information Sciences. https://doi.org/10.1016/j.jksuci.2019.08.008

20. Uzodike, U. O., \& Maiangwa, B. (2012). Boko Haram terrorism in Nigeria : causal factors and central problematic. African Renaissance, 9(1), 91-118.

21. Varin, C. (2018). Turning the tides of war: The impact of private military and security companies on Nigeria's counterinsurgency against Boko Haram. African Security Review, 27(2), 144-157. https://doi.org/10.1080/10246029.2018.1489863

22. Yang, Y., Tang, J., Leung, C. W., Sun, Y., Chen, Q., Li, J., \& Yang, Q. (2015, February 9). RAIN: Social Role-Aware Information Diffusion. Twenty-Ninth AAAI Conference on Artificial Intelligence. Twenty-Ninth AAAI Conference on Artificial Intelligence. https://www.aaai.org/ocs/index.php/AAAl/AAAl15/paper/view/9384 